\title{
Pilot Study of an e-Cohort to Monitor Adverse Event for Patient with Hip Prostheses from Clinical Data Warehouse
}

\author{
Thibault DHALLUIN ${ }^{\mathrm{a}, \mathrm{b}, 1}$, Marie ANSOBORLO ${ }^{\mathrm{a}, \mathrm{b}}$, Philippe $\operatorname{ROSSET}^{\mathrm{b}, \mathrm{c}}$, \\ Hervé THOMAZEAU ${ }^{\mathrm{d}}$, Marc CUGGIA ${ }^{\mathrm{e}}$ and Leslie GUILLON ${ }^{\mathrm{a}, \mathrm{b}}$ \\ ${ }^{a}$ Department of Medical Information, University Hospital of Tours, Tours, France \\ ${ }^{\mathrm{b}}$ Medical school, University of Tours, EA 7505 EES, Tours, France \\ ${ }^{\mathrm{c}}$ Department of Orthopedic Surgery, University Hospital of Tours, Tours, France \\ ${ }^{\mathrm{d}}$ Federation of Orthopaedic Surgery, University Hospital Sud, 35203 Rennes, France \\ e Univ Rennes, CHU Rennes, Inserm, LTSI - UMR 1099, F-35000 Rennes, France
}

\begin{abstract}
Hip arthroplasty represents a large proportion of orthopaedic activity, constantly increasing. Automating monitoring from clinical data warehouses is an opportunity to dynamically monitor devices and patient outcomes allowing improve clinical practices. Our objective was to assess quantitative and qualitative concordance between claim data and device supply data in order to create an ecohort of patients undergoing a hip replacement.

We performed a single-centre cohort pilot study, from one clinical data warehouse of a French University Hospital, from January 1, 2010 to December 31, 2019. We included all adult patients undergoing a hip arthroplasty, and with at least one hip medical device provided. Patients younger than 18 years or opposed to the reuse of their data were excluded from the analysis. Our primary outcome was the percentage of hospital stays with both hip arthroplasty and hip device provided. The patient and stay characteristics assessed in this study were: age, sex, length of stay, surgery procedure (replacement, repositioning, change, or reconstruction), medical motif for surgery (osteoarthritis, fracture, cancer, infection, or other) and device provided (head, stem, shell, or other).

We found 3,380 stays and 2,934 patients, $96.4 \%$ of them had both a hip surgery procedure and a hip device provided. These data from different sources are close enough to be integrated in a common clinical data warehouse.
\end{abstract}

Keywords: Data Warehousing; Data Management; Arthroplasty, Replacement, Hip; Equipment Safety

\section{Introduction}

The number of Total Hip Arthroplasty (THA) is constantly increasing in France [1]. With the reinforcement of the European regulatory constraints, there is a need to improve follow-up of patients with hip prostheses with an efficient post-marketing surveillance [2]. Complications are rare but have important consequences on the patients' quality of life (surgical site infection, deep vein thrombosis, dislocation).

1 Corresponding Author, Thibault DHALLUIN, Department of Medical Information, University Hospital of Tours, Tours, France. Medical school, University of Tours, EA 7505 EES, Tours France 2, boulevard Tonnellé - 37044 Tours cedex 9, France, E-mail : T.DHALLUIN@chu-tours.fr 
In France, there is no national cohort of hip replacement patients of sufficient quality to be reused for surveillance purposes [3]. This lack of data makes it difficult to combine clinical information on patients and technical data on devices to identify the determinants of rare and/or delayed but severe complications such as surgical site infection or luxation. Moreover, the classic manual constitution of a cohort is a long expensive process requiring a high workload for the teams. Moreover, a dynamic link between patients and outcomes could allow real-time updated surveillance [4-6].

The digitization of medical records and health examinations represents now a large re-usable data sources to monitor adverse event. These digital data could be stored following FAIR principles, in clinical data warehouses in order to provide a technical, regulatory, interoperability and security framework adapted [7,8]. The use of our data warehouses already makes it possible to track drug complications and it seems necessary to study the possibility of tracking complications after an joint replacement $[9,10]$. Since the 2007 regulation, the references of implanted medical devices are listed and linked to the identification of the patient for device safety purposes [11]. Our hypothesis was that the device data were comprehensive and of sufficient quality to track the different components of a hip device to monitor adverse event through a clinical data warehouse.

Our objective was to assess quantitative and qualitative concordance between claim data and device supply data in order to integrate them into a data warehouse.

\section{Method}

We performed a single-centre pilot cohort study between January 1, 2010 and December 31, 2019, using the clinical data warehouse of one University Hospital using a large data warehouse software eHOP [12]. We included all patients' stays of hip arthroplasty procedure or with at least one hip medical device provided. Patients younger than 18 years or opposed to the reuse of their data were excluded from the analysis.

The coverage obtained by hospital stays from matching two different sources was assessed: the surgical procedure data came from claim data (hospital discharge database PMSI), completed with a French version of the Current procedural terminology (CPT) and the medical device data came from the pharmacy supply software. The consistency of using inclusion criteria from different sources was measured by identifying the percentage of hospital stays having both a hip replacement procedure and a hip device provided.

A descriptive analysis of the main characteristics was performed: age, sex, length of stay, surgery act (replacement, repositioning, change, or reconstruction), surgery motif (arthrosis, fracture, cancer, infection, osteonecrosis or other main diagnosis) and device provided (head, stem, shell, or other) following Giori et al [6]. This descriptive analysis specifically specified the source of each of these data and missing data.

In order to know in which medical and surgical situation we were able to obtain each component, we crossed the hospital stays according to the main cause of surgery and the presence of a head, a stem and a shell device. In the same way we crossed the type of surgical procedure and the presence of a head, a stem and a shell device to evaluate the completeness according to the type of surgical procedure. 


\section{Results}

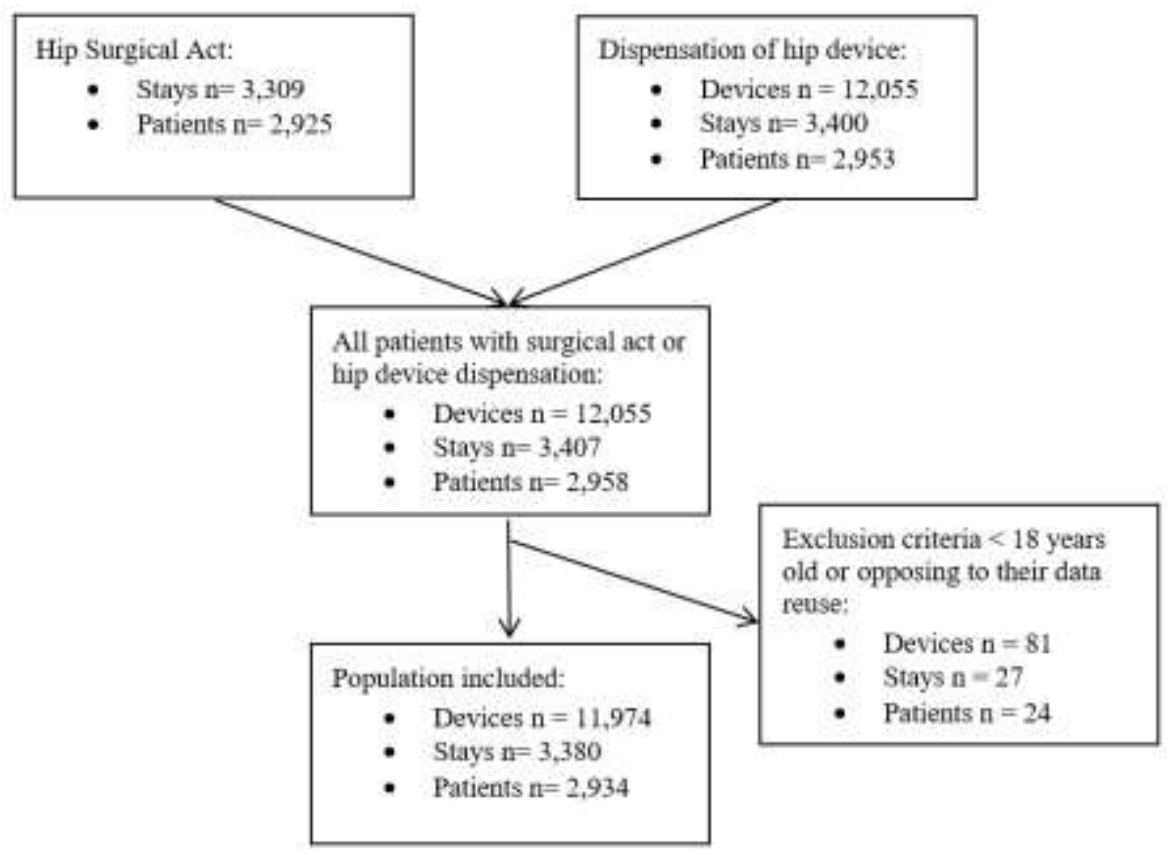

Figure 1. Flow chart

Table 1. Main characteristics of the population

\begin{tabular}{|c|c|c|c|}
\hline \multicolumn{2}{|c|}{ Features } & Descriptive Data & Source of Data \\
\hline \multicolumn{4}{|c|}{ Stays $(\mathrm{N}=\mathbf{3 , 8 8 0})$} \\
\hline Age (m & $(\mathrm{sd}))$ & $71.3(13.8)$ & Hospital discharge database \\
\hline \multicolumn{4}{|c|}{ Sex } \\
\hline- & Female $(\%)$ & $1,910(43.5 \%)$ & \\
\hline- & Male $(\%)$ & $1,470(56.5 \%)$ & \\
\hline \multicolumn{2}{|c|}{ Length of stay (mean (sd)) } & $10.3(10.5)$ & \\
\hline \multicolumn{3}{|c|}{ Surgery procedure } & Claim data French CPT \\
\hline- & Replacement (\%) & $2,642(78.2 \%)$ & (Common procedure terminology) \\
\hline- & Change $(\%)$ & $475(14.1 \%)$ & \\
\hline- & Reconstruction (\%) & $86(1.7 \%)$ & \\
\hline- & Repositioning (\%) & $57(1.7 \%)$ & \\
\hline- & Missing value (\%) & $120(3.5 \%)$ & \\
\hline \multicolumn{3}{|c|}{ Cause of surgery } & Claim data ICD-10 \\
\hline- & Arthrosis (\%) & $1,864(55.1 \%)$ & \\
\hline- & Fracture $(\%)$ & $875(25.9 \%)$ & \\
\hline- & Infection $(\%)$ & $153(4.5 \%)$ & \\
\hline- & Cancer $(\%)$ & $85(2.5 \%)$ & \\
\hline- & Osteonecrosis (\%) & $58(1.7 \%)$ & \\
\hline- & Other $(\%)$ & $327(9.7 \%)$ & \\
\hline- & Missing value (\%) & $18(<1 \%)$ & \\
\hline \multicolumn{3}{|c|}{ Device $(N=11,974)$} & Device supply data \\
\hline- & Femoral Head (\%) & $3,444(28.8 \%)$ & \\
\hline- & Femoral Stem $(\%)$ & $3,055(25.5 \%)$ & \\
\hline- & Acetabular Cup (\%) & $4,952(41.3 \%)$ & \\
\hline- & Others $(\%)$ & $523(4.4 \%)$ & \\
\hline
\end{tabular}


Over the study period, 3,407 hospital stays corresponded to a hip replacement; of which 3,309 have a medical / surgical procedure and 3,400 have a medical device provided. Moreover, 27 stays were excluded because they were under 18 years old or opposed to the data reuse. We obtained 3,380 hospital stays, including 11,974 hip devices implanted.

The coverage between the medical / surgical procedure and the device supply data was $96.4 \%$. Among the 3,380 hospital stays, 120 (3.6\%) stays without hip surgery procedure were found.

The mean age of the patients was 71.3 years old years with $56.5 \%$ women and $43.5 \%$ men. The mean length of stay was 10.3 days. $55.1 \%$ of the stays were for hip arthrosis and $25.9 \%$ for femoral neck fracture (table 1).

Table 2. Presence of hip devices according to the main cause of surgery.

\begin{tabular}{lllllll} 
& Arthrosis & Fracture & Infection & Cancer & \multicolumn{2}{l}{ Osteonecrosis Others } \\
\hline $\begin{array}{l}\text { N } \\
\text { Device }\end{array}$ & 1,864 & 875 & 153 & 85 & 58 & 327 \\
Head (\%) & $1,843(98.9 \%)$ & $871(99.5 \%)$ & $150(98 \%)$ & $84(98.8 \%)$ & $58(100 \%)$ & $293(89.6 \%)$ \\
Stem (\%) & $1,801(96.6 \%)$ & $851(97.3 \%)$ & $84(54.9 \%)$ & $32(37.6 \%)$ & $56(96.6 \%)$ & $168(51.4 \%)$ \\
Shell (\%) & $1,844(98.9 \%)$ & $864(98.7 \%)$ & $143(93.5 \%)$ & $80(94.1 \%)$ & $58(100 \%)$ & $299(91.4 \%)$ \\
\hline
\end{tabular}

Table 3. Presence of hip devices according to the surgical procedure.

\begin{tabular}{lllll} 
& Replacement & Change & Reconstruction & Repositioning \\
\hline $\begin{array}{l}\text { N } \\
\text { Device }\end{array}$ & 2,642 & 475 & 86 & 57 \\
Head (\%) & $2,633(99.7 \%)$ & $428(90.1 \%)$ & $85(98.8 \%)$ & $56(98.2 \%)$ \\
Stem (\%) & $2,608(98.7 \%)$ & $263(55.4 \%)$ & $47(54.7 \%)$ & $49(86 \%)$ \\
Shell (\%) & $2,632(99.6 \%)$ & $425(89.5 \%)$ & $84(97.7 \%)$ & $57(100 \%)$ \\
\hline
\end{tabular}

Over $90 \%$ of the hospital stays had a femoral head and shell references. The presence of femoral stems was more inconstant, especially in procedures performed for surgical site infections or cancer. Similarly, we found device references in over $98 \%$ of joint replacement procedures. In more complex procedures such as prosthesis change, reconstruction and repositioning the references were found in 50 to $100 \%$ of the cases (table 2-3).

\section{Discussion}

With $96.4 \%$ coverage, we obtained close data between the hospital stays obtained by medical-surgical procedures and those obtained by medical devices. The devices were found for more than $90 \%$ of the heads and shells and almost entirely for the most common clinical cases such as joint replacement in first intention for osteoarthritis.

In the case of change or repositioning surgery, the prosthesis stems were not systematically replaced and the procedure might concern only the head and the acetabulum, which might explain the procedures without stem. In the reconstructive surgery scenario, devices data included batch devices, but did not include custom prostheses, which may explain the missing stem devices in some femoral cancer reconstruction.

These results are obtained from a single centre, but these data might also be close in other centres because claims data are collected in the same way for all French healthcare facilities and device data are subject to the same traceability regulations in France. The data obtained are subject to the usual bias of information, when handling 
the hospital discharge database, and in the same way the device supply data the errors of information are ever possible. The number of medical records with missing device data was reasonable to be manually reviewed and corresponded to case-by-case situations, either due to data input errors or surgery where one of the pieces was actually not dispensed. The data reuse of medical device dispensed for a postmarketing surveillance and epidemiological purposes seemed possible.

The reliability of these data seemed high enough to be integrated in our clinical data warehouse. Among the next challenges, the organization of devices according to a common thesaurus seems complex considering the heterogeneous characteristics of medical devices and the lack of international common thesaurus.

\section{References}

[1] Putman S, Girier N, Girard J, Pasquier G, Migaud H, Chazard E. Épidémiologie des prothèses de hanche en France: analyse de la base nationale du PMSI de 2008 à 2014. Revue de Chirurgie Orthopédique et Traumatologique. 2017 Nov 1;103(7):S90.

[2] EUR-Lex - 32017R0745 - EN - EUR-Lex, (n.d.). https://eur-lex.europa.eu/eli/reg/2017/745/oj/eng (accessed August 3, 2021).

[3] Registre des prothèses de hanche, SOFCOT. (n.d.). https://www.sofcot.fr/cnp-cot/registre-desprotheses-de-hanche (accessed August 3, 2021).

[4] Resnic FS, Matheny ME. Medical devices in the real world. The New England journal of medicine. 2018 Feb 15;378(7):595-7.

[5] Dhalluin T, Fakhiri S, Bouzillé G, Herbert J, Rosset P, Cuggia M, Grammatico-Guillon L. Role of realworld digital data for orthopedic implant automated surveillance: a systematic review. Expert Review of Medical Devices. 2021 Aug 3(just-accepted).

[6] Giori NJ, Radin J, Callahan A, Fries JA, Halilaj E, Ré C, Delp SL, Shah NH, Harris AH. Assessment of Extractability and Accuracy of Electronic Health Record Data for Joint Implant Registries. JAMA network open. 2021 Mar 1;4(3):e211728-.

[7] Wilkinson MD, Dumontier M, Aalbersberg IJ, Appleton G, Axton M, Baak A, Blomberg N, Boiten JW, da Silva Santos LB, Bourne PE, Bouwman J. The FAIR Guiding Principles for scientific data management and stewardship. Scientific data. 2016 Mar 15;3(1):1-9.

[8] Madec J, Bouzillé G, Riou C, Van Hille P, Merour C, Artigny ML, Delamarre D, Raimbert V, Lemordant P, Cuggia M. eHOP Clinical Data Warehouse: From a Prototype to the Creation of an InterRegional Clinical Data Centers Network. Studies in health technology and informatics. 2019 Aug 1;264:1536-7.

[9] Bouzillé G, Morival C, Westerlynck R, Lemordant P, Chazard E, Lecorre P, Busnel Y, Cuggia M. An Automated Detection System of Drug-Drug Interactions from Electronic Patient Records Using Big Data Analytics. InMedInfo 2019 Aug 21 (pp. 45-49).

[10] Sylvestre E, Bouzillé G, Chazard E, His-Mahier C, Riou C, Cuggia M. Combining information from a clinical data warehouse and a pharmaceutical database to generate a framework to detect comorbidities in electronic health records. BMC medical informatics and decision making. 2018 Dec;18(1):1-8.

[11] Décret $\mathrm{n}^{\circ}$ 2006-1497 du 29 novembre 2006 fixant les règles particulières de la matériovigilance exercée sur certains dispositifs médicaux et modifiant le code de la santé publique (Dispositions réglementaires) - Légifrance, (n.d.). https://www.legifrance.gouv.fr/jorf/id/JORFTEXT000000463293 (accessed October 1, 2021).

[12] Benchimol EI, Smeeth L, Guttmann A, Harron K, Hemkens LG, Moher D, Petersen I, Sørensen HT, von Elm E, Langan SM. The REporting of studies Conducted using Observational Routinely-collected health Data (RECORD) statement. Zeitschrift für Evidenz, Fortbildung und Qualität im Gesundheitswesen. 2016 Oct 1;115:33-48. 